\title{
Students Access to Quality Science Teachers in Secondary Schools in the South West Region of Cameroon: An Appraisal from the Perspective of Students Academic Achievement
}

\author{
Mbanjo Martin Ewange \\ B.Ed, M.Ed, PhD (In view), University of Buea, Buea, Cameroon
}

\begin{abstract}
This study investigated and described students' access to quality science teachers in secondary schools in the south west region of Cameroon: an appraisal from the perspective of students' academic achievement. The descriptive analytic research design was used to gather information in which scholarly articles, books and other sources relevant to the issue under investigation, were reviewed. A sample of - ten secondary schools in the Fako Division of the South West Region of Cameroon was considered to appraise the study via literature. The sample /'schools represented both rural and urban schools; high, medium and poorly performing schools; single sex and co-educational schools; and boarding and day schools. Altogether the selection covered a wide geographical and socio-economic consideration within Fako Division of the South West Region of Cameroon. The secondary schools in the study sample comprised schools where students have to make a choice between Science and Arts options at some stage in the secondary years.
\end{abstract}

Literature relating to science teachers quality and students performance was effectively reviewed. Findings revealed that students performance within the geographical scope of investigation were relatively very poor in the sciences. It was realised that teacher quality is an indispensible factor or contributor of student's performance. Key note on low students performances were recorded on large classes that overburden and overload the teacher, poor training, poor qualifications or inadequate in-service programs, teachers behaviour and lack of visual aids, textbooks, chemicals or needed teaching material.

Based on these, it was recommended that science teachers should be evenly distributed so that they will not be concentrated in only a few schools while others lack them, only qualified and experienced science teachers should handle foundation lessons for secondary school students, teachers should be sensitized on the need to generate practical work in the laboratories in which girls play a major role and that science teachers should have regular in-service courses to re-orient them on their teaching methodologies and acquaint them with the use of new chemicals and new equipment so that they sustain the interest of all students.

Keyword: Science, Teachers, Academic, Achievement, Students

\section{INTRODUCTION}

Cameroon and the international community identify education as the prime means through which meaningful and sustainable development can be achieved. This explains why educational stake holders have been galvanizing resources and time in developing this sector. It has been widely acknowledged that education, or the acquisition of knowledge and skills, together with research and innovation are key devices for economic prosperity and sustainable growth (Aghion, David, \& Foray, 2009).

The relevance of science education to the future of society is likely to be considerably more far-reaching than its influence on human affairs in the past. Some of the pressing problems of society today are related to the rapid decline in the quality of global environment, depletion of natural resources, increasing poverty, hunger and illiteracy in many countries and regions of the world. Solutions based on science and technology is likely to provide remedial 
measures to some of these problems, and yet science and technology as we understand today, are not available to a vast human population especially teachers teaching this field in schools. It is essentially in the advanced world that science and technology have contributed to individual fulfillment, the wellbeing of communities, and to the health of nations. A high percentage of the human population does not understand science or its utility, and its potential for economic and social development. There is a tendency to get impressed with certain products of technology that may bring in superficial prosperity, but a proper understanding of technological innovation and of the way science and technology are related to society is important for real progress of all countries, particularly the developing ones. Such an understanding is retarded today by the barriers impending the sharing and the use of scientific and other knowledge necessary to make decisions and choices. That is that science education attempts to wrestle with three mutually contradictory requirements. On the one hand it wants to demonstrate the tremendous liberatory power that science offers - a combination of the excitement and thrill that comes from the ability to discover new knowledge, and the tremendous cinsights nand understanding of the material world that it provides. Yet its mechanism for achieving this aim is to rely on a dogmatic, authoritarian and extended science education where students must accept what they are told as unequivocal, uncontested and unquestioned. Only when they finally begin practicing as scientists and enter the inner sanctum will the workings of science become more transparent. Moreover, its foundationalist emphasis on basic concepts rather than the grand ideas of science means that any sense of its cultural achievement is simply forgotten.

\section{STATEMENT OF THE PROBLEM}

Research suggests that teachers play a pivotal role in improving education, as teachers are the single most important factor in predicting individual student achievement levels (Anderson \& Helms, 2001; Darling-Hammond, 2002; Mendro, 1998; National Commission on Teaching and America's Future, 1996). According to Murnane and Steele (2007), today's policy challenge requires more than placing enough adults in front of classrooms; today's policy challenge requires that teachers in classrooms be equipped to have strong, positive impacts on student learning. As such, teacher quality is central to the discussion of improving education for students in today's schools. When students get into the classrooms, they are now expected to have access to the curriculum. That is access to effective teaching and learning.

However with the acute shortage of qualified science teachers in most of our schools particularly in rural areas as reported by Regional Pedagogic inspectors. One begin to wonder how effective the teaching and learning of science is going on in such schools. As a result of these inadequacies, students may not end up acquiring the knowledge and skills like their counterparts in other areas. This might lead not only to poor academic performance but might put students at a disadvantage position in the labour market as well as in their personal development. Poor performances by students in the sciences might lead to drop outs and unemployment. Failure to acquire the knowledge and skills from the science subjects might affect student's progress in their future careers in the sciences such as engineering and medicine given that, the skills acquired forms the bases or foundation on which their future careers are built on. These are some of the problems that may arise as a result of inappropriate access to quality science teachers. It is the gravity of these problems and its impact to learning and students' achievements that this study attempts to investigate.

\section{Purpose of the Study}

The purpose of this study is to investigate the extent to which student's access to quality science teachers in secondary schools in Cameroon affects student's academic achievement

\section{Research Question}

Does Students access to quality science teachers in secondary schools in Cameroon influence students' academic achievement?

\section{BACKGROUND}

Educational development in Cameroon after the Federal administration and after the unitary state saw an increase in the general population and that of school going age in particular (Tambo, 2003). This increase in population resulted to an increase in more socio-economic challenges to grapple with. The government and international partners like the United Nations (UN) thought that education remains the prime means for meaningful development and recommended an increase in educational access so as to satisfy the quest for education by the increasing 
population as well as in a bid to enhance socioeconomic development. The years that followed saw an increase in newly created secondary schools nationwide.

Students' access to qualified teachers particularly in the sciences has proven to be an important factor that determines positive outcome. In a study carried out in the United States, Wayne and Youngs (2003) reviewed studies that related teacher quality to student's achievement. They found out that when qualified teachers with degrees were examined, students' outcomes were positive in mathematics.

In another study carried out by Rice (2003) in which she focussed on five attributes of teacher quality namely certification, experience, preparation programmes and degrees, course work, and teacher test scores. In discussing her findings, Rice (2003) concluded the following;

$>$ Teacher certification seems to matter for high school mathematics

$>$ Teacher experience matters, particularly in the first five years of teaching.

$>$ Teachers course work, whether subject specific or in pedagogy, appears to have a positive impact on student learning at all grade levels but subject specific course matters most in secondary education.

$>$ It should be noted that a qualified teacher is one who has under gone training in both subject specific area and in pedagogy.

In another study to investigate teacher quality as correlates of students academic performance in Biology in senior secondary schools in Ondo StateNigeria; the researchers Akinfe E, Olofeminyi, O.E, and Fashiku C.O (2000) after data analysis, found that the role of professionally qualified/trained teachers is an important teacher quality which enhances students' academic achievement in Biology. The findings revealed that several schools in the population of the study lacked modern instructional materials without which effective teaching and learning cannot be utilized and teacher experience significantly influence students academic performance.

In many nations, science and technology education are becoming increasingly identified as the background for economic stability and growth. In the past, in developed and developing countries, only the "brighter" students have been encouraged to pursue science knowledge. Science has been viewed (and still is by many) as knowledge accessible to only the elite few. Now, however, many countries are subscribing to the goal of "science for all." Science is increasingly being viewed as a subject of life-long utility to all students, whether or not they enter science-related careers. In the developing world, a more science literate populace is perceived as being better equipped to contribute to economic and societal development through informed decision-making in such areas as: agricultural production, nutrition and health, land and resource management, population control and industrial growth The "science for all" movement is driving curricular change at varying speeds in different countries and the process of school science curricula redefinition la in motion worldwide. This redefinition is being accompanied by a re-examination of the classroom role of the teacher - supported by findings from cognitive psychology on how students actually learn science - from "sage on the stage, to guide on the side." In many countries, science teachers, particularly at the lower secondary level (grades 7/8- 10/11), are unprepared to teach the existing science courses in a teacher-centered classroom (Ware, 1992). How can they be expected to teach unfamiliar science, organized across disciplines, using unpractised techniques and skills, to "different" kinds of students? It is not just the "science for all" movement that is driving curricular change. The old disciplinary boundaries are fading in the dynamic world of science research. Biology is becoming chemistry which is becoming biology, touching on physics which shades into chemistry. It is in the bridging sciences of biochemistry, biophysics, and materials science where much of the vitality of modern science is best displayed. Yet, on a worldwide basis, both the university courses of study and the upper secondary (11/12-12/13) science stream courses tend to remain obstinately defined as chemistry, physics, and biology as they were delineated 30 years ago. Thus, whether science is to be taught to future scientists, or to future citizens, there is a pressing need to ensure that the secondary science teacher, whose role is so crucial has the educational background necessary to rise to both challenges. The issue is not that there are no well-prepared secondary science teachers. The issue is that the purposes of science education are changing, the content and its delivery are evolving, and the expectations for student achievement are rising. This is true for both developing and developed countries (Ware, 1992). The last ten years have seen a re-evaluation of the 
teaching/ learning interaction for AU school subjects. Ten years ago, it was still general by accepting that 'teaching was telling, learning was listening, and knowledge was facts" (Lanier, 1992). This view of the teaching/learning exchange is being replaced by a more "agile" pedagogy, which recognizes the students' own active role in the learning process, and views the teacher as a facilitator of this process. Today's students will be tomorrow's citizens. They will enter a workforce that needs the talents of better educated students, capable of life-long self-directed learning and of contnbuting to sound decision-making for their community and their country. If more students are to be taught to function at higher levels of cognition, they will need to be taught by teachers who can themselves operate as life-long, self-directed learners. Thus, because of relatively recent changes in our views of both science bad teaching, even the very best of teacher training facilities needs to re-examine and re-evaluate the currency of its mission and its curriculum. There is widespread concern about the outcomes of science education at school. For example, the representatives of industry say that they need more high-grade scientists, technicians, and engineers if any country is to compete successfully in technology-intensive global markets. Whatever their career intentions, too few young people do much science at school once it ceases to be compulsory. This leads to fewer applications for science degrees and reduces the supply of science graduates. Just as importantly, the number of young people entering non-graduate occupations involving science or technology are reduced, which leads to skills shortages in many sectors. The Review undertaken by Sir Gareth Roberts in 2002 summarised the scale of this problem. It also identified some of its causes. In particular it noted the lack of women choosing to study science-related subjects, reports by students of their poor experience of science education, the shortage of well-qualified and enthusiastic science teachers, and young people's poor image of sciencerelated careers. The Roberts Report led to the government's ten-year 'Science and Innovation Investment Framework 2004-2014. Yet while the strategy makes some useful references to teacher supply and curriculum issues, it offers little guidance on how its ambitious aims are to be achieved. The majority of science education research conducted to date has addressed secondary schooling, although research into primary school science identifies similar issues and is referred to where available. It is important that 'science education is needed for citizenship'. It would be designed to develop the curiosity of young people about the natural world around them, and help them acquire a broad appreciation of the important ideas and explanatory frameworks of science and how scientific enquiry works. The processes and ideas of science are of great importance to everybody in three ways. The first is in their personal lives, for example so that they can validly identify the components of a healthy life-style. The second is in their civic lives, so that they take an informed part in social decisions, for example on future options for electricity Kubilay Kaptan and Ozden Timurlenk / Procedia - Social and Behavioral Sciences 51 ( 2012 ) 763 - 771765 supply. The third is in their economic lives, where they need to be able to respond positively to changes in the science-related aspects of their employment. If the major purpose of science education is to increase the flow of specialist scientists, technologists and engineers, it could be argued that young people with a special talent in science should be identified as early as possible and provided with a separate, specialised, and highly focused science education. Such people share the general need for a broad science education and should not be cut off from it. In any case, there are no valid and reliable ways in which such young people may be identified. Some who show early promise subsequently fade, whilst the talents of others emerge later on. Young people today show an appetite for a broadly-based education based on themes of proven interest, and developing a range of transferable skills. They would resist any attempt to foreclose their choices. The best way forward is to provide the highest grade of 'science education for citizenship' for all students. If that education is sufficiently challenging and interesting, genuine high achievement will become more widespread and will become apparent through students' creativity, lateral thinking, and persistence. The young people who demonstrate such achievement will be be increasingly motivated to follow science-related careers. What analysis and evidence are available to help promote high quality science education for all future citizens? There must be a greater recognition of what students bring to their studies and how different teaching methods engage with their learning. The diversity in students' learning strategies must be met by the use of suitable teaching methods. The curriculum must be closely matched to the purposes of 'science education for citizenship'. The assessment of what has been learned must be closely matched to the purposes of that curriculum. And, central to all of these aims, the supply, 
development, and retention of high quality teachers must be actively pursued.

Methods employed by teachers to teach science subjects in secondary schools are to a very large extent influenced by the kind of resources and facilities available in the school. The teaching methods, in turn, influence the level and quality of participation and performance in by students, particularly girls. In general, where resources and facilities - teachers, textbooks, laboratories, chemicals, tools and equipment, teaching aids, stores, offices etc. - are inadequate, the teaching approach tends to be teacher-centered and thus to a greater extent affects teachers quality. This type of approach is heavily dominated by the teacher as he or she lectures on the subject, gives notes and demonstrates the practical aspects of the lesson. The students remain passive participants expected to listen and observe only. The teacher, therefore, is the sole source of knowledge for the pupils. This can be risky in the event that the teacher is inadequately informed on the subject or is not adequately trained in the art of communication.

A good quality secondary education is critical for developing the required knowledge, skills and attitudes to support health and well-being as well as sustainable livelihoods and inclusive economic growth. The development of higher order cognitive and affective skills is also key, as many low-income countries aspire to become knowledge economies. A key target of the recently adopted Sustainable Development Goal for education (Goal Four) is to ensure by 2030 that all girls and boys complete free, equitable and quality primary and secondary education leading to relevant and effective learning outcomes. Whilst there has been progress in expanding access to primary education in the context of the Millennium Development Goals, this has put additional pressure on the urgent need to expand access to secondary education and a consequent improvement in the quality of teachers. At present, millions of learners are in schools without science teachers and many others are even denied access to a good quality secondary education including girls, learners in urban slum and rural areas, learners with disabilities and members of ethnic minorities. In 2012, the average gross enrolment ratio for lower secondary for sub-Saharan Africa was 50\% (53\% for boys, 46\% for girls) (EFA Global Monitoring Report team, 2015). For those who do gain access, many enter secondary education with low levels of learning including basic literacy and numeracy. Teachers also often have weak subject and pedagogical knowledge on entering the profession contributing to poor learner outcomes. Improving the professional capabilities of educators to deliver quality teaching in challenging delivery contexts is key for raising the quality of education for all including the most marginalized.

Contrary to the 1966 study by James Coleman, as cited in Whitehurst (2002), that suggested that differences in teachers did not matter, recent studies have shown that teacher quality is the single most important school-related factor in student achievement. In 1996, value added assessments were conducted by Sanders and Rivers (Coleman, as cited in Archer, 1999) to answer the question of whether teachers matter. Math teachers in grades 3, 4, and 5 in two urban school districts in Tennessee were examined to determine the average amount of academic growth of students in their classrooms. From this data, teachers were identified and grouped as being the most effective teachers, the top $20 \%$, and the least effective teachers, the bottom $20 \%$. The progress of these students assigned to these effective and least effective teachers were documented over a consecutive three year period. The results revealed that at the end of 5th grade, math students assigned to the high performing teachers scored in the 83rd percentile; students assigned to the low performing teachers scored in the 29th percentile (Whitehurst, 2002). In 1997, a similar study related to long-term teacher effectiveness was conducted in Dallas, Texas. Researchers extended the study across a wide range of grades, used three different urban school districts and two different methods of determining teacher effectiveness, and yielded similar results, emphasizing the measurable difference that better teachers have on student performance (Bembry, Jordan, Gomez, Anderson, \& Mendro, 1998). In effect, these findings differ from the research of James Coleman in the 1960s that was interpreted as such, "the general message taken from Coleman's findings is that socioeconomic status largely determines student achievement ... a and what schools do doesn't matter very much, because in the end poor kids learn very little and rich kids learn a lot" (Archer, 1999, p. 3). The results of these longitudinal studies show that teachers are an influential factor of student achievement, regardless of socioeconomic status and even school location. In other words, a student having an ineffective teacher several years in a row can be at 
an academic disadvantage, which affects his/her progress for years; whereas, a student with a highly effective teacher can have positive gains in academic progress for years to come. Various research studies (Blair 2000b; Darling-Hammond 2000; Hanushek 1971,) reveal that factors such as cognitive ability, subject matter knowledge, knowledge of teaching and learning, licensure, and teaching behaviors in the classroom are related to teacher quality and increased student achievement. The purpose of this paper is to identify the indicators of quality teachers and their impact on student achievement by conducting a literature review.

The system theory is well rooted in a study of this type. According to Houghton et al (1975) a system is 'a set of objects together with relationships between the objects and between their attributes. All systems except the smallest have 'subsystems' and all but the largest have supra systems' which are their environments. Systems may be open or closed. An open system is that which is related to and makes exchange with its environment, while a closed system is not related to and does not make exchanges with its environment (Mbua, 2003). Also closed systems are characterized by an increase in entropy end in stability while open system is a good example of an open system given that it has interdependent components (subsystems) as well as makes exchanges with the environment.

In the context of this study, the secondary education equally is equally an open system which has interdependent components as well as makes exchanges with the environment.

The components that make up the secondary school science curriculum here include qualified teachers, the use of appropriate teaching methods; teaching resources, learning activities, assessment strategies etc. These components interact in an interdependent and holistic manner to enhance effective teaching and learning and consequently student's achievement. If one of the components is absent or ineffective, then the purpose of effective teaching and learning may be hindered. For instance if qualified science teachers are not there to teach or if appropriate teaching resources are absent, then effective teaching and learning might not take place. This may consequently affect student's performance. This implies that for access of the secondary school science curriculum to be attained all the above mentioned components should be effectively present in order to enhance effective teaching and learning which shall consequently improve students' performance.

\section{METHODOLOGY}

The present study involved a descriptive analytic research design. A literature review surveys scholarly articles, books and other sources relevant to a particular issue, area of research, or theory, and by so doing, providing a description, summary, and critical evaluation of these works. Literature reviews are designed to provide an overview of sources you have explored while researching a particular topic and to demonstrate to your readers how your research fits into the larger field of study. This study has surveyed and described literature relating to students access to quality science teachers in secondary schools in Cameroon and its implication to students academic achievement. The study covered a sample of ten secondary schools in the Fako Division of the South West Region of Cameroon. The sample schools represented both rural and urban schools; high, medium and poorly performing schools; single sex and co-educational schools; and boarding and day schools. Altogether the selection covered a wide geographical and socio-economic consideration within Fako Division. The secondary schools in the study sample comprised schools where students have to make a choice between Science and Arts options at some stage in the secondary years

\section{FINDINGS}

Research findings show a positive relationship between science teacher's cognitive ability and student achievement. A study by Hanushek (1971) presents an interesting view of teachers. In his model, the teacher characteristic that appears to contribute to increased student academic performance is a teacher's verbal ability. For both second and third grade teachers, the score on a verbal ability test plays two roles: first it is a measure of communicative ability; second, it can be taken as a quick measure of overall intelligence and ability. Thus, overall intelligence or general ability seems important regardless of formal training. There is more research that shows that teachers who have strong verbal ability or score high on verbal tests impact student achievement more than teachers with lower scores.

Subject matter knowledge is another variable that is related to teacher effectiveness. In a major study conducted by Wenglinsky on the relationship between 
indicators of teacher quality and the performance of 8th graders, teacher educational backgrounds appear crucial to the student performance on science portions of the 1996 National Assessment of Educational Progress (Blair, 2000b). Upon examining approximately 15,000 scores of 8 th grade students' science performances, students whose teachers had college majors or minors in either math or science scored 39\% higher than those whose teachers lacked such preparation. In addition, Monk, as cited in Darling-Hammond (2000), using data on 2,829 students from the Longitudinal Study of American Youth, found that teachers' content preparation, as measured by coursework in the subject field, is positively related to student achievement in mathematics and science.

While these studies appear to support the relationship between subject matter and teacher effectiveness, other researchers as cited in Darling-Hammond (2000), find that the connection between the two variables have mixed results. Studies of teachers' scores on the subject matter tests of the National Teacher Examinations (NTE) have found no consistent relationship between this measure of subject matter knowledge and teacher performance as measured by student outcomes. Byrne (as cite in Darling Hammond, 2000) did thirty related studies between subject matter knowledge to student achievement. The results were mixed with 17 showing a positive relationship and 14 showing no relationship. Also, studies by Ashton and Crocker (1987) found only 5 out of 14 studies they reviewed to show a positive relationship between subject matter and teacher performance. Despite the mixed findings, it may be safe to conclude that teachers who hold College majors or minors in the subject area that they are teaching, especially in math and science, positively impact student learning in those subject areas.

While the evidence that subject matter makes a difference is mixed, research shows that teacher education coursework has a positive effect on student achievement. A study was conducted on the teacher education program at Arkansas Tech University to determine the extent to which education and subject matter course work predicted the teaching performance of student teachers completing the program (Ferguson \& Womack, 1993). Findings indicate that course work in teacher education makes a difference in teaching performance; education coursework is a more powerful predictor of teacher effectiveness than measures of expertise in content area subjects. Furthermore, Ashton and Crocker (1987) compared professional education and academic subject area coursework to determine whether there was a relationship between the two variables and teaching effectiveness. The findings revealed that there was a positive relationship in four out of seven studies when researchers related the number of credits in education coursework. In contrast, a positive relationship was found in only five out of fourteen studies when the number of college credits earned in a subject area compared with student performance in that area. Furthermore, teachers' professional knowledge and skills can be developed through professional development and in-service programs to achieve successful student outcomes (King \& Newmann, 2000). For example, at Lewis Elementary School in Texas, professional development focused on teaching strategies to teachers in reading and math, strategies that the students can use themselves. Over a 4-year period, students' reading and math achievement improved dramatically across a range of social backgrounds (King \& Newmann, 2000). Studies cited in DarlingHammond (2000) find that teacher opportunities to participate in professional development in content specific areas linked to the curriculum made an impact on teaching and student achievement. Therefore, teacher preparation education coursework is beneficial and worthwhile in making an educational difference.

Research on teacher behaviors in the classroom demonstrated that effective teachers tend to be those who are able to use a variety of teaching strategies and demonstrate a flexible style rather than a single, rigid approach. Studies cited in Darling-Hammond (2000) suggest that it is the expertises of the teachers that make learning occur for students. In general, effective teachers are able to adjust their teaching style to fit the needs and style of different learners because they have a wide repertoire of approaches and strategies, such as direct teaching, modeling interactive teaching strategies, cooperative learning techniques, and experienced-based and skill-based approaches. As cited in Darling-Hammond (2000), other variables that have been found to be important are teacher clarity, enthusiasm, task-oriented behavior, and higher order thinking. In effect, high quality instruction depends on competence and attitudes of each individual teacher. In the report of 
the National Commission on Teaching and America's Future the standards and assessments that have emerged from the National Commission on Teaching and America's Future identify that an effective teacher should have an understanding of how students learn and develop, skills in using a range of strategies; sensitivity and effectiveness in working with students from diverse backgrounds, the ability to work well with parents and other teachers, and assessment expertise capable of discerning how well children are doing, what they are learning and what needs to be done next to move them along (Darling-Hammond, 1996). Therefore, the fact remains that teaching behaviors and practices facilitate student learning.

Quality teachers are an indispensable resource in the teaching and learning of sciences in secondary schools but from literature and findings in this study, they can be rendered ineffective by any one or a combination of the following factors:

$>$ large classes that overburden and overload the teacher

$>$ poor training, poor qualifications or inadequate inservice programs

> lack of visual aids, textbooks, chemicals or needed teaching material

The study found out that there is a great shortage of science teachers at the secondary school level, and the few there are, have to be shared by a large number of students which puts a heavy workload on the teachers. At the same time, the study revealed that most science teachers are male. There are relatively few female teachers teaching sciences in secondary schools and hence girls and society at large lack what would be the most immediate female role models in science education. For example, of the 145 teachers contacted in the 10 secondary schools considered in this study, only 33 were females. More seriously is the fact that more than $50 \%$ of students were not satisfied with the delivery of lessons by their teachers and equally pointed to the fact that performances in most science subjects is usually lower than in arts disciplines.

It is equally noticed that this problem is not unique to schools in Fako Division of the South West Region of Cameroon but is visible in other divions of the country and beyond.

This general shortage of science teachers has created a situation were the few available are too loaded with work that seriously affects quality and consequent performance of students The study revealed that most teachers at secondary schools are inadequately trained and almost never participate in any in-service training. Most lack creativity and initiative and will not improvise where there are no readymade visual aids. Most are ignorant of' unique problems relating the delivery of science lessons. Some lack competence in the use of equipment available in their schools and so such equipment remains unused. Practical work requires time to plan, try out, set for the class and remove and clear up after the lesson. Some teachers, being poorly motivated, find it difficult to spare time for such a process.

It emerged from group discussions with parents and students of secondary schools that some teachers misuse school time on extra-curricular activities intended to supplement their meager incomes. Private tuition in the evenings has become a significant part of school life. Parents complained that as a result, some teachers have no time for students from poor families.

In addition, many teachers complain that science syllabuses, mainly at the secondary level, are inordinately long and that there is not sufficient time to cover the syllabus adequately. This is often the pretext for skipping practical work, even where equipment is available, on the basis that practical work takes up too much class time. The unwillingness to engage in practical work is bolstered by examinations which test learned knowledge and not practical skills

\section{CONCLUSIONS}

Given the important findings of this research policymakers and educators need to invest in critical areas that impact the quality of teacher and the quality of teaching. While it is no secret that better teachers produce better learning, educational reform must work toward restructuring and reinventing teacher preparation and professional development by connecting clinical work in schools with knowledge about what works for teaching and subject-matter knowledge. If we are going to hold students to standards, we need to be able to ensure that the teachers who work with them will also be able to teach to those standards. Thirdly, teachers do matter, and their cognitive ability and knowledge of the subject matter and of teaching and learning, licensure, and teaching behaviors in the classroom are related to teacher quality. Major changes in the areas of 
recruitment, preparation, licensing, teacher support and opportunities for professional growth need to occur in order for teaching to improve, thus inevitably and positively affecting the most important variable of all, the student.

\section{Recommendations}

1. Science teachers should be evenly distributed so that they will not be concentrated in only a few schools while others lack them.

2. Only qualified and experienced science teachers should handle foundation lessons for secondary school students.

3. Teachers should be sensitized on the need to generate practical work in the laboratories in which girls play a major role.

4. Science teachers should have regular in-service courses to re-orient them on their teaching methodologies and acquaint them with the use of new chemicals and new equipment so that they sustain the interest of all students

\section{REFERENCES}

1. Archer, J. (1999). Sanders101. Education Week, 18(34), 26-28. Retrieved November 16, 2003, from Academic Search Tre Elite: http://www.epnet.com/academic/asearchelite.asp

2. Ashton. P., \& Crocker, L. (1987). Systematic study of planned variations: The essential focus of teacher education reform. Journal of Teacher Education, 38, 2-8.

3. Bembry, K. L., Jordan, H. R., Gomez, E., Anderson, M. C., \& Mendro, R. L. (1998). Policy implications of long term teacher effects on student achievement. Retrieved November 16, 2003, from http://dallasisd.org/depts/inst_research/aer98rm1.h tml Blair, J. (2000a).

4. Certification found valid for teachers. Education Week, 20(8), 1. Retrieved November 16, 2003, from Academic Search Elite: http://www.epnet.com/academic/asearchelite.asp Blair, J. (2000b).

5. ETS study links effective teaching methods to test-score gains. Education Week, 20(8), 24. Darling-Hammond, L. (1996). What matters most: A competent teacher for every child. Phi Delta Kappan, 78(3), 193-200.

6. Darling-Hammond, L. (2000). Teacher quality and student achievement: A review of state policy evidence. Education Policy Analysis Archives, 8(1), Darling-Hammond, L., \& Youngs, P. (2002).

7. Defining "Highly qualified teachers": What does "Scientifically-based research" actually tell us? Educational Researcher, 31(9), 13-25.

8. Ferguson, P., \& Womack. S. T. (1993). The impact of subject matter and education coursework on teaching performance. Journal of Teacher Education, 44(1), 55-63.

9. Greenwald, R., Hedges, L. V., \& Laine, R. D. (1996). The effect of school resources on student achievement. Review of Educational Research, 66(3), 361-396.

10. Hanushek, E. A. (1971). Teacher characteristics and gains in student achievement: Estimation using micro data. The American Economic Review, 61(2), 280-288.

11. King, M. B., \& Newmann, F. M. (2000). Will teacher learning advance school goals? Phi Delta Kappan, 81(8), 576-580. Rotherham, A. J., \& Mead, S. (2003).

12. Teacher quality: Beyond no child left behind. A response to Kaplan and Owings (2002). NASSP Bulletin, 87(635), 65-76.

13. U.S. Department of Education, Office of Elementary and Secondary Education. (2002). No Child Left Behind Act of 2001. Washington, DC: Author. Whitehurst, G. J. (2002, June).

14. Raising student achievement: The evidence of high quality teaching. Remarks presented at the Standards-based Teacher Education Project 2002 Summer Conference. Retrieved November 16, 2003 from: http://www.cbe.org/pdf/STEP2002whitehurst.pdf

15. Brown, J.S., Collins, A. \& Duguid, S. (989). Situated Cognition and the Culture of Learning. Educational Research, 18(1), 32-42.

16. Engestrom, Y., Mietinnen, R., and Runamaki R-L. (Ed's 1999) Perspectives on Activity theory. Cambridge: Cambridge University Press.

17. Gagne, R. M (1985) The conditions of learning $\left(4^{\text {th }}\right.$ ed). New York: Holt, R Rinehart Winston.

18. Lave, J. Situated Learning: Legitimate Peripheral Participation. Cambridge, Uk: Cambridge University press. 
International Journal of Trend in Scientific Research and Development (IJTSRD) ISSN: 2456-6470

19. Mac Ojong. T.T (2008) Philosophical and Historical foundations of Education in Cameroon 1844-1960: Limbe. Design House

20. Mbua, F.N. (2003) Educational Administration! Theory and Practice. Limbe: Design House.

21. Mkpa, M.A. (1990) Curriculum Development and Implementation. Owerri: Totan Publishers Limited
22. Tambo, L, I (2012) Principles and Methods of Teaching Limbe: Limbe: Design House

23. Tambo, L. I (2003) Cameroon National Education Policy Since the 1995 forum: Limbe: Design House

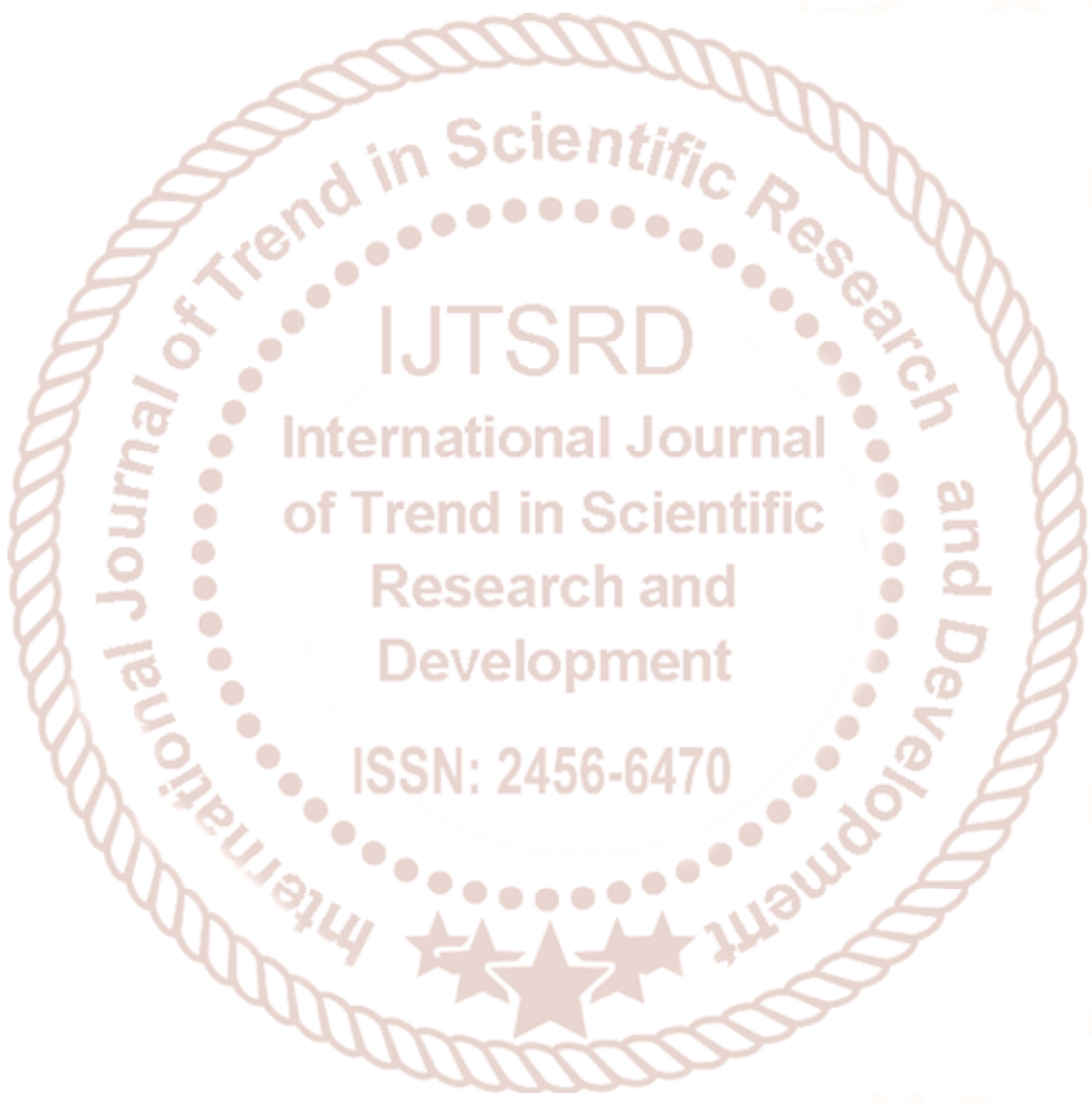

